\title{
OUTCOME OF PHACOEMULSIFICATION WITH INTRAOCULAR LENS IMPLANTATION IN PATIENTS WITH HIGH MYOPIA
}

\author{
Sunil Kumar1, Samrin Sarwar², Rajiv Kumar ${ }^{3}$ \\ ${ }^{1}$ Assistant Professor, Department of Ophthalmology, RIMS, Ranchi, Jharkhand. \\ 2Junior Resident, Department of Ophthalmology, RIMS, Ranchi, Jharkhand. \\ 3Professor, Department of Ophthalmology, RIMS, Ranchi, Jharkhand.
}

\begin{abstract}
OBJECTIVE: To evaluate the visual and refractive outcomes of phacoemulsification with intraocular lens (IOL) implantation in highly myopic eyes and to assess the intraoperative and postoperative complications.

SETTINGS: Tertiary care Centre Ranchi, India.

METHODS: Consecutive patients with high myopia were retrospectively studied for outcomes and complications after phacoemulsification and IOL implantation.

RESULTS: The study included 125 eyes of 89 patients (53 females and 36 males) with a mean age of $56.01 \pm 9.51$ years and mean follow-up of $19.45 \pm 4.07$ months. The mean axial length was $29.58 \pm 2.57 \mathrm{~mm}$ and power of the IOL ranged from $-4.00 \mathrm{D}$ to +17.00 D. The mean preoperative logMAR Best corrected visual acuity (BCVA) was $0.82 \pm 0.26$ which improved to $0.38 \pm 0.29$ at one month and to $0.43 \pm 0.33$ at last follow-up, the improvement in vision was statistically significant $(\mathrm{P}<0.0001$, paired t test). Postoperatively, 80 eyes (64\%) had a BCVA between 0.00 logMAR (20/20) and 0.30 logMAR (20/40). Pre-existing myopic chorioretinal degeneration (13.6\%) was most common factor causing decreased visual acuity. The mean spherical equivalent at one month postoperative was $-0.06 \pm 1.28$ D. The complications included posterior capsule rupture $(5.6 \%)$, zonular dehiscence $(1.6 \%)$, retinal detachment (1.6\%), cystoid macular edema (8.8\%) and posterior capsule opacifications (10.4\%).
\end{abstract}

CONCLUSIONS: Phacoemulsification with intraocular lens implantation is a safe and effective procedure to improve patients visual acuity in those with high myopia.

KEYWORDS: Myopia, Cataract, Phacoemulsification, Intraocular lens, Retinal detachment.

HOW TO CITE THIS ARTICLE: Sunil Kumar, Samrin Sarwar, Rajiv Kumar. "Outcome of Phacoemulsification with Intraocular Lens Implantation in Patients with High Myopia”. Journal of Evolution of Medical and Dental Sciences 2015; Vol. 4, Issue 92, November 16; Page: 15771-15774, DOI: 10.14260/jemds/2015/2279.

INTRODUCTION: High myopia is defined as an eye whose axial length $(\mathrm{AL})$ is greater than $26 \mathrm{~mm}$ or refractive power of -6.00 diopters (D) or greater. ${ }^{1}$ Myopia is widely known to be a degenerative disease occurring as a result of distension of the globe, mainly at the posterior pole. ${ }^{2}$

High myopia is also a risk factor for cataract formation which is mostly posterior subcapsular or nuclear sclerosis type..$^{3,4}$ Also cataract occurs at younger age in myopic patients. 5

Cataract surgery in patients with high myopia often have poor visual outcome because of presence of chorioretinal degenerations and have a higher risk of complications such as retinal detachment (RD), cystoid macular edema, posterior capsular opacification compared with emmetropic eyes. ${ }^{6}$ Highly myopic eyes often have a posterior staphyloma which can give an erroneously long $\mathrm{AL}$, when measured with the standard A-scan ultrasound. ${ }^{7}$

Financial or Other, Competing Interest: None.

Submission 28-10-2015, Peer Review 29-10-2015,

Acceptance 06-11-2015, Published 16-11-2015.

Corresponding Author:

Dr. Sunil Kumar,

Assistant Professor,

Regional Institute of Ophthalmology,

RIMS, Ranchi,

Jharkhand.

E-mail: drsunilpgi12@yahoo.com

DOI:10.14260/jemds/2015/2279.
This could lead to an error in lens power calculation and residual post-operative hyperopia. Using an optical biometry for measurement of AL tends to be more accurate. ${ }^{8} \mathrm{~A}$ postoperative refractive goal of a mild amount of residual myopia, such as $-0.5 \mathrm{D}$, can be helpful to avoid a hyperopia.

In this study we investigated the visual and refractive outcomes as well as intra and postoperative complications in highly myopic eyes after phacoemulsification and intraocular lens (IOL) implantation.

MATERIALS AND METHODS: Consecutive patients with high myopia (Axial length greater than or equal to $26 \mathrm{~mm}$ ) who underwent cataract extraction by phacoemulsification and IOL implantation between January 2012 and July 2014 at Regional institute of ophthalmology, Rajendra institute of medical sciences, Ranchi were retrospectively analyzed.

Patients completing at least 12 months of follow-up after phacoemulsification were included in the study. Approval was taken from the Institute ethics committee for the study.

Patients with history of keratorefractive surgery, ocular trauma and who had follow-up of less than 12 Months were excluded from the study.

All patients underwent complete ophthalmological examination. These included uncorrected visual acuity (UCVA) and best corrected visual acuity (BCVA), Keratometry, A-scan biometry, intraocular pressure (IOP) using applanation tonometry, anterior segment examination 
using slit lamp biomicroscopy and dilated fundus examination using direct and indirect ophthalmoscopy.

A-scan was performed using immersion ultrasound methods. The IOL power was determined using the SRK-T formula. Cataract extraction was performed using phacoemulsification under topical or peribulbar anaesthesia.

A one piece or three piece foldable hydrophobic acrylic IOL was implanted in all the patients. All surgeries were done by a single surgeon (SK). Informed consent was taken from all the patients before performing the surgery. The surgical techniques, intraoperative complications, preoperative and postoperative visual acuities, postoperative complications and the causes of impaired visual acuity after surgery were analysed.

SURGICAL TECHNIQUE: All patients received topical moxifloxacin $0.5 \%$ four times during 24 hours before surgery. Pupil dilation was achieved using topical combined tropicamide $0.8 \%$-phenylephrine $5.0 \%$, cyclopentolate $1.0 \%$, and ketorolac $0.5 \%$ every 30 minutes starting 90 minutes before surgery. In all cases, standard clear corneal phacoemulsification was performed using topical or peribulbar anesthesia.

Two side-port corneal incisions were created 180 degrees apart with 15-degree disposable blades; the main incision was made with a $2.8 \mathrm{~mm}$ keratome.

The anterior chamber was formed with a high-viscosity ophthalmic viscosurgical device (Sodium hyaluronate 1.4\%). A $5.0 \mathrm{~mm}$ to $5.5 \mathrm{~mm}$ continuous curvilinear capsulorhexis was created. Cortical cleavage hydrodissection was performed with nucleus rotation. The lens nucleus was emulsified using a direct phaco-chop or a stop-and-chop technique. The cortical material was removed by bimanual irrigation/aspiration (I/A). A single piece or three piece hydrophobic acrylic IOL was implanted in the capsular bag. A subconjunctival injection of gentamicin $20 \mathrm{mg}$ and dexamethasone $4 \mathrm{mg}$ was given at the end of surgery. Postoperatively, patients received topical moxifloxacin $0.5 \%$ four times a day and topical prednisolone acetate $1.0 \%$ six times a day and then tapered over 4 to 6 weeks.

STATISTICAL ANALYSIS: Statistical analysis was performed using SPSS for Windows software (Version 16.0, SPSS Inc., Chicago, IL, USA) Snellens visual acuities were converted to logMAR acuity for statistical analysis. The paired $t$ test was used to analyze visual acuity before and after surgery. $\mathrm{P}$ values $<0.05$ was accepted as statistically significant.

RESULTS: The study included 125 eyes of 89 patients of high myopia. There were 36 males (40.4\%) and 53 females (59.6\%) patients. The mean age of the patients was $56.01 \pm 9.51$ (range 38-80) years (Figure 1). The mean followup was $19.45 \pm 4.07$ months (Range 13-28 months). The mean axial length as determined by A-scan biometry was 29.58 \pm 2.57 (Range 26.01-33.15) $\mathrm{mm}$ (Figure 2). The calculated power of the IOL ranged from-4.00D to+17.00D.

Intraoperatively posterior capsule rupture with vitreous loss occurred in 7(5.6\%) eyes. Two port limbal anterior vitrectomy was performed in eyes with posterior capsule rupture.
IOL was then implanted in the sulcus over the capsulorrhexis margin, and optic capture was done to ensure proper centration. Two of the patients had weak zonules observed intraoperatively. It was managed with placement of capsular tension ring (CTR) after performing capsulorrhexis and IOL was placed in the bag.

Table 1 shows preoperative BCVA, postoperative BCVA at 1 month and postoperative BCVA at last follow-up. The mean preoperative logMAR BCVA was $-0.82 \pm 0.26$. It increased to $0.38 \pm 0.29$ at one month postoperative and to $0.43 \pm 0.33$ at last follow-up. The improvement in BCVA from preoperatively to postoperatively at 1 Month and at last follow-up was statistically significant $(\mathrm{P}<0.0001$, paired $\mathrm{t}$ test). Postoperatively, 80 eyes (64\%) had a BCVA between $0.00 \operatorname{logMAR}(20 / 20)$ and $0.30 \log$ MAR (20/40). The mean spherical equivalent at one month postoperative was$0.06 \pm 1.28 \mathrm{D}$.

Table 2 shows causes of decreased postoperative visual acuity. Pre-existing myopic chorioretinal degeneration was present in $17(13.6 \%)$ eyes and it was most common factor causing decreased visual acuity. Posterior capsular opacification requiring Nd: YAG capsulotomy developed in $13(10.4 \%)$ eyes. Retinal detachment occurred in $02(1.6 \%)$ eyes and clinically significant cystoid macular edema occurred in $11(8.8 \%)$ eyes.

\begin{tabular}{|c|c|c|c|c|}
\hline $\begin{array}{c}\text { Snellen } \\
\text { VA }^{+}\end{array}$ & $\begin{array}{c}\text { logMAR } \\
\text { VA }\end{array}$ & $\begin{array}{c}\text { Pre- } \\
\text { operative } \\
\text { Eyes n (\%) }\end{array}$ & $\begin{array}{c}\text { Postop } \\
\text { month } 1 \\
\text { Eyes n (\%) }\end{array}$ & $\begin{array}{c}\text { Last post } \\
\text { op } \\
\text { follow-up } \\
\text { Eyes n } \\
\text { (\%) }\end{array}$ \\
\hline $\begin{array}{c}20 / 20- \\
20 / 40\end{array}$ & $0.0-0.3$ & $03(2.4 \%)$ & $80(64 \%)$ & $74(59.2 \%)$ \\
\hline $\begin{array}{c}20 / 60- \\
20 / 100\end{array}$ & $0.4-0.7$ & $39(31.2 \%)$ & $28(22.4 \%)$ & $25(20 \%)$ \\
\hline $\begin{array}{c}20 / 125- \\
20 / 200\end{array}$ & $0.8-1.0$ & $67(53.6 \%)$ & $14(11.2 \%)$ & $19(15.2 \%)$ \\
\hline$>20 / 200$ & $>1.0$ & $16(12.8 \%)$ & $03(2.4 \%)$ & $07(5.6 \%)$ \\
\hline
\end{tabular}

Table 1: Preoperative and postoperative BCVA*

*BCVA-best corrected visual acuity, †VA-visual acuity, $\neq$ Postop-postoperative

\begin{tabular}{|c|c|}
\hline Condition & Eyes, n (\%) \\
\hline $\begin{array}{c}\text { Chorioretinal } \\
\text { degeneration }\end{array}$ & $17(13.6 \%)$ \\
\hline PCO $^{*}$ & $13(10.4 \%)$ \\
\hline $\mathrm{CME}^{\dagger}$ & $11(8.8 \%)$ \\
\hline Glaucoma & $4(3.2 \%)$ \\
\hline $\mathrm{RD}^{\ddagger}$ & $2(1.6 \%)$ \\
\hline Optic atrophy & $1(0.8 \%)$ \\
\hline \multicolumn{2}{|c|}{ Table 2: Conditions causing decreased postoperative } \\
visual acuity \\
\hline
\end{tabular}

*PCO-posterior capsule opacification + CME-cystoid macular edema $\neq$ RD- retinal detachment.

DISCUSSION: High myopia is a risk factor for presenile cataract formation. ${ }^{5,9}$ The age distribution graph (Figure 1) in our study also depicts very clearly the younger population of patients with high myopia requiring cataract surgery. 
Calculating the IOL power is one of the most important issues in high myopic patients. Inaccuracies in axial length may be due to presence of posterior staphyloma and poor fixation from macular diseases. ${ }^{10}$ Use of optical biometry is more accurate in such cases. ${ }^{8}$ Also SRK/T and Holladayformulas are recommmended for IOL calculation because a large hyperopic shift may occur with the SRK-II formula. ${ }^{7}$

In our study, IOL power calculation was based on immersion ultrasound biometry and use of SRK/T Formula. Postoperative spherical equivalent was within 1.0 diopters of refractive target in $82 \%$ of eyes. Other studies have reported that the postoperative SE was within 1.0 diopters of refractive target in $53.2-70 \%$ of highly myopic eyes undergoing cataract surgery. ${ }^{10-13}$

The results of post-operative BCVA were found to be satisfactory, $64 \%$ of the eyes at 1 month and $59.2 \%$ of the eyes at last follow-up had BCVA $20 / 40$ or better and only $5.6 \%$ of the eyes at last follow-up had BCVA less than 20/200. The results were comparable to earlier studies which reported that $52.7-71.2 \%$ of eyes with high myopia could reach BCVA of $20 / 40$ or better after cataract surgery. ${ }^{10,11,14}$ However, Ku WC et al. ${ }^{15}$ determined that patients might have less favorable outcome after cataract surgery due to several retinal changes found in high axial myopia.

The most common cause of poor BCVA in our study was preexisting myopic chorioretinal degenerations which was present in $13.6 \%$ of the eyes. So we can counsel the patients about poor visual outcome in highly myopic eyes with preexisting myopic chorioretinal degenerations. Some of the patients were found to have optic atrophy, glaucoma, posterior capsular opacification, cystoid macular edema and retinal detachment on post-operative follow-up examinations. These could also might have led to the decreased BCVA in some of our patients.

We also encountered some intra-operative complications. The most common complication was posterior capsular rupture accompanied with vitreous loss seen in $5.6 \%$ of the eyes. Anterior vitrectomy was performed and intraocular lens was placed in the sulcus over the capsulorrhexis margin, and optic capture was done to ensure proper centration in all of these. Posterior capsular rupture has been reported in $2.6-5.5 \%$ of the eyes in earlier studies. ${ }^{10,11,16}$ High rate of posterior capsule rupture might be due to increased fluctuations of anterior chamber depth in highly myopic eyes. Zonular dehiscence occurred in $1.6 \%$ of the eyes which was managed with use of CTR. Myopic eyes are predisposed to zonular weakness, which could have led to the complication.

Retinal detachment occurred in $2(1.6 \%)$ of eyes postoperatively. Both eyes that developed $\mathrm{RD}$ had posterior capsular rupture and vitreous loss intra-operatively. One eye developed RD at 4 months and other at 8months postoperatively. Both patients underwent pars plana vitrectomy by vitreo-retinal surgeon. Although they achieved good anatomical result, the BCVA was not better than counting fingers in both eyes. Earlier studies have reported incidence of pseudophakic RD between $0.26-3.8 \%$ in eyes with axial length greater than $26 \mathrm{~mm} .17,18,19$ on long-term follow up.
Cystoid macular edema occurred in $8.8 \%$ of the eyes post-operatively which resolved after treatment with topical steroids and NSAIDS.

Highly myopic eyes have a propensity for posterior capsular opacification, so patients should be counselled about the need for laser capsulotomy after otherwise successful cataract surgery. Posterior capsular opacification was noted in $10.4 \%$ of the eyes in our study during the follow-up which subsequently had to undergo Nd:YAG laser capsulotomy.

The rate of Nd:YAG laser capsulotomy was comparable to previous studies. Tsai et al and Tosi et al. ${ }^{14,20}$ had reported incidence of Nd:YAG laser capsulotomy $11.5 \%$ and $16.4 \%$ respectively.

CONCLUSION: phacoemulsification with intraocular lens implantation is a safe and effective procedure to improve patients visual acuity in those with high myopia and cataract. Pre-existing myopic chorioretinal macular degeneration and occurrence of posterior capsular rupture intra-operatively are the most important factors affecting the best corrected visual acuity post-operatively.

\section{REFERENCES:}

1. Zejmo M, Forminsca-Kapuscik M, Pieczara E, Filpek E, Mrukwa-Kominek E, Samochoweik-Donocik E, et al. Etiopathogenesis and management of high degree myopia. Part I. Med Sci Monit 2009:15:RA199-RA202.

2. Saw SM, Gazzard G, Shih-Yen EC, Chua WH. Myopia and associated pathological complications. Ophthalmic Physiol Opt 2005; 25:381-391.

3. Lim R, Mitchell P, Cumming RG. Refractive associations with cataract: the Blue Mountains Eye Study. Invest Ophthalmol Vis Sci. 1999 Nov; 40(12):3021-6.

4. Wong TY, Klein BE, Klein R, Tomany SC, Lee KE. Refractive errors and incident cataracts: the Beaver Dam Eye Study. Invest Ophthalmol Vis Sci. 2001; 42(7):1449-54.

5. Praveen MR, Shah GD, Vasavada AR, Mehta PG, Gilbert C, Bhagat G. A study to explore the risk factors for the early onset of cataract in India. Eye (Lond). 2010; 24(4):68694.

6. Sohee Jeon, Hyun Seung Kim. Clinical Characteristics and Outcomes of Cataract Surgery in Highly Myopic Koreans. Korean J Ophthalmol 2011; 25(2):84-89.

7. Seward H, Packard r, Allen d. Management of cataract surgery in high myope. Br J Ophthalmol 2001; 85:13721378.

8. Landers J, Goggin M. comparision of refractive outcomes using immersion ultrasound biometry and IOL master biometry. Clin Experiment Ophthalmol 2009; 37:566-569.

9. Hoffer KJ. Biometry of 7,500 cataractous eyes. Am J Ophthalmol. 1980; 90:360-8.

10. Zuberbuhler B, Seyedian M, Tuft S. Phacoemu-lsification in eyes with extreme axial myopia. J Cataract Refract Surg 2009; 35:335-340.

11. Serpil Akar, Kemran Gok, Sukru Bayraktar, Vedat Kaya, Yasar Kucuksumer, Cigdem Altan et al. Phacoemulsification in high myopia. Saudi Med J 2010; 31(10):1141-1145. 
12. Ji YH, Lu Y, Lu GS, Luo Y, Wang M. Phacoemulsification and the negative power of intraocular lenses in extremely myopic eyes. Zhonghua Yan Ke Za Zhi 2005; 41:196-199.

13. Pomberg ML, Miller KM. Preliminary efficacy and safety of zero diopter lens implantation in highly myopic eyes. Am J Ophthalmol 2005; 25:315-320.

14. Tsai CY, Chang TJ, Kuo LL, Chou P, Woung LC. Visual outcomes and associated risk factors of cataract surgeries in highly myopic Taiwanese. Ophthalmologica. 2008; 222:130-135.

15. Ku WC, Chaung LH, Lai CC. Cataract extraction in high myopic eyes. Chang Gung Med J 2002; 25:315-320.

16. Li CY, Chen YC, See LC, Linn KK. Visual outcome after cataract surgery in extremely high axial myopia. Ann Ophthalmol 2007; 39:27-35.
17. Alio JL, Ruiz-Moreno JM, Shabayek MH, Lugo FL, Abd EL, Rahman AM. The risk of retinal detachment in high myopia after small incision coaxial phacoemulsification. Am J Ophthalmol. 2007; 144:93-98.

18. Jacobi FK, Hessemer V. Pseudophakic retinal detachment in high axial myopia. J Cataract Refract Surg. 1997; 23:1095-1102.

19. Ripandelli G, Scassa C, Parisi V, Gazzangia D, D Amico DJ, Stripe M. Cataract surgery as a risk factor for retinal detachment in very highly myopic eyes. Ophthalmology 2003; 110:2355-2361.

20. Tosi GM , Casprini F, Malandrini A , Balesstrazzi A. Phacoemulsification without intraocular lens implantation in patients with high myopia:long term results J Ctaract Refract Surg 2003;29:1127-1131.

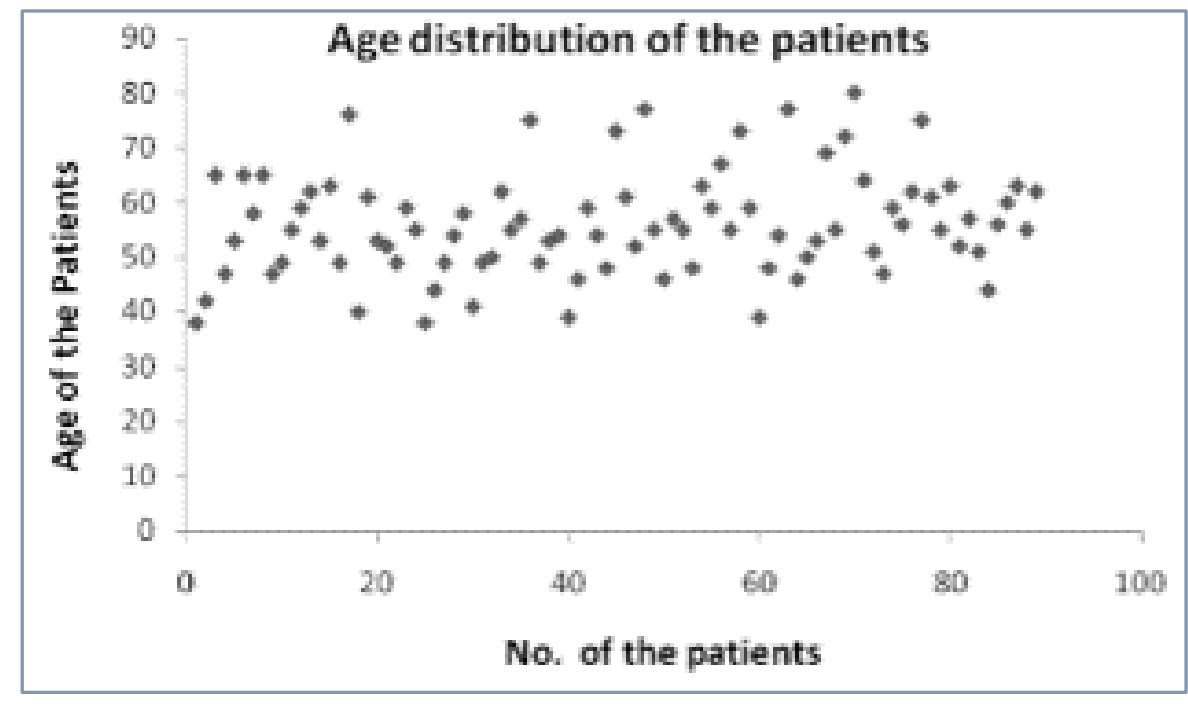

Figure 1: Showing age distributions of patients

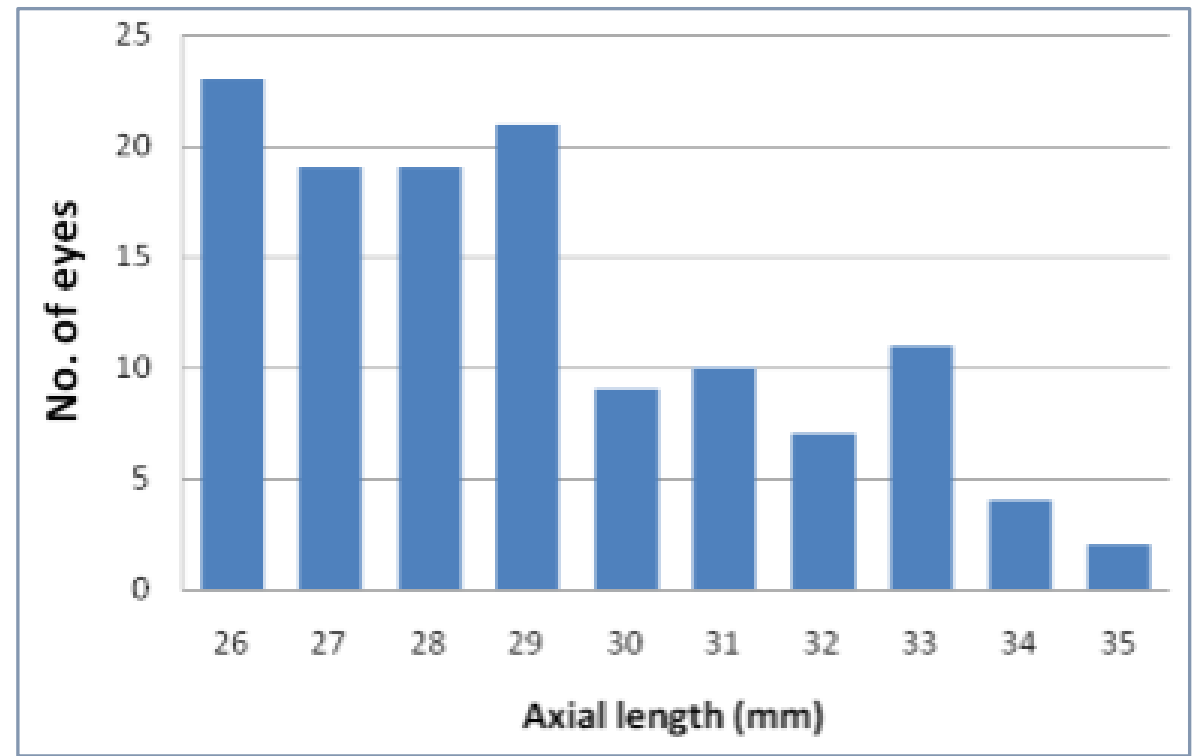

Figure 2: Showing axial length as recorded with immereison ultrasound 